\title{
Biphasic Effects of Adrenal Steroids on Learned Helplessness Behavior Induced by Inescapable Shock
}

\author{
Silvia ME Kademian', Anahi E Bignante', Patricia Lardone', Bruce S McEwen² and Marta Volosin*,' \\ 'Departamento de Farmacología, Facultad de Ciencias Químicas, Universidad Nacional de Córdoba, Haya de la Torre esq, Medina Allende, \\ Ciudad Universitaria, Córdoba, Argentina; ${ }^{2}$ Harold and Margaret Milliken Hatch Laboratory of Neuroendocrinology, The Rockefeller University, \\ New York, NY, USA
}

\begin{abstract}
Corticosterone (CS) has been shown to regulate behavior in the learned helplessness $(\mathrm{LH})$ paradigm. Here we provide evidence for a $U$ shaped relationship between the increasing doses of CS administered and escape failures in the LH model. Replacement with CS (20$400 \mu \mathrm{g} / \mathrm{ml}$ in drinking water) in adrenalectomized (ADX) animals was utilized to examine how the selective activation of mineralocorticoid (MR) and glucocorticoid (GR) receptors is related to the behavioral impairments induced by inescapable shock (IS). Available MR and GR levels were determined in hippocampal cytosol by radioligand binding assays. Non-CS replaced ADX animals showed a high percentage of escape failures assessed $48 \mathrm{~h}$ after IS. A CS does of $100 \mu \mathrm{g} / \mathrm{ml}$ given to ADX animals markedly reduced escape failures and resulted in an almost total reduction of available MR associated with a partial reduction of GR. However, the administration of aldosterone (ALDO), a selective MR agonist, was not sufficient to restore normal coping behavior. Moreover, an important role for GR was further shown by means of the specific GR antagonist, RU 38486, which blocked the reduction of LH in ADX rats that were given $100 \mu \mathrm{g} / \mathrm{ml}$ CS. Higher doses of CS given to ADX rats reinstated the LH behavior, and SHAM rats that produced stress CS levels also produced LH behavior. The results indicate a U-shaped dose response function with both negligible and high CS levels being associated with LH behavior. Hence, along with a moderate reduction of available GR level in the cytosol, a large decrease in $M R$ availability seems to be necessary to prevent the acquisition and expression of $L H$. However, very high reduction of available GR is associated with $\mathrm{LH}$ behavior.
\end{abstract}

Neuropsychopharmacology (2005) 30, 58-66, advance online publication, 20 October 2004; doi: I 0. I 038/sj.npp. 1300577

Keywords: learned helplessness; hippocampus; corticosteroid receptors; corticosterone; rats

\section{INTRODUCTION}

Adrenal steroids play an important role in regulating both learned and unlearned fear and anxiety (Korte 2001; Calvo et al, 1998; Calvo and Volosin, 2001) and alterations in the balance between Type I or mineralocorticoid receptors (MR) and Type II or glucocorticoid receptors (GR) in the brain appear to play a role in these behaviors as well as in the etiology of depression and anxiety (de Kloet et al, 1988; Korte, 2001). MR and GR are expressed throughout the central nervous system, with GR showing a more widespread distribution and MR showing a discrete localization, such as in neurons of the hippocampus, regions of the

\footnotetext{
*Correspondence: Dr M Volosin, Departamento de Farmacología, Facultad de Ciencias Químicas, Universidad Nacional de Córdoba, Haya de la Torre esq, Medina Allende, Ciudad Universitaria, (5000) Córdoba, Argentina, Tel: + 5435 I 4334437 ext. 163, Fax: + 5435 I 4334420, E-mail: mlv@fcq.unc.edu.ar

Received 26 November 2003; revised 16 August 2004; accepted 18 August 2004

Online publication: 23 August 2004 at http://www.acnp.org/citations/ Npp08230403545/default.pdf
}

amygdala, and brain stem (Ahima and Harlan, 1990; Ahima et al, 1991).

MR and GR mediate different aspects of corticosterone (CS) action: for example, hippocampal MR is responsible for the maintenance of stability in the stress response system throughout the circadian cycle (Ratka et al, 1989; Dallman et al, 1992), whereas GR facilitates the recovery of the system after the exposure to a stressful stimulus (de Kloet et al, 1988). Moreover, the activation of $\mathrm{MR}$ in neurons from the hippocampal CA1 region stabilizes local excitability while it is reduced by GR activation (Joels $e t a l$, 1998). Also, the optimal induction of long-term potentiation (LTP) - a plasticity phenomenon occurring in the hippocampus that is related to learning and memory processes depends on moderate levels of steroids with a predominant activation of MR (Pavlides et al, 1995; Diamond et al, 1998). This phenomenon could help to explain that in intact rats, spatial learning is exceptionally sensitive to the manipulation of central adrenal steroid receptors (Oitzl, 1998). Thus, for spatial learning, MR activation was related to the strategies adopted during the test, while GR activation was associated with the consolidation of learning (Oitzl and de Kloet, 1992; Oitzl et al, 2001). However, increased and 
sustained levels of glucocorticoids when administered out of the context of the learning task may interfere with the acquisition or retrieval, thus extinguishing a learned response (Lupien and McEwen, 1997; de Kloet et al, 1999; de Quervain et al, 2000).

Much evidence supports the hypothesis that CS has two means of operation: a proactive one, through which CS maintains the basal activity of the axis and controls the sensitivity of the stress response system. Specifically, under these basal conditions, the majority of MR and only a small proportion of $\mathrm{GR}$ are occupied. In the second, reactive mode, CS contributes to the culmination of the system activation. In this last situation, a greater amount of GR is occupied (De Kloet et al, 1998).

On a cellular level, CS modulates the excitability of hippocampal neurons (Joels and de Kloet, 1992) and regulates LTP in a biphasic fashion. Interestingly, one of the first studies aimed to evaluate a possible relationship among corticosteroid levels and LTP generation demonstrated that it adopts an inverted U-shaped curve function, since the basal levels of CS or the administration of MR agonists induce LTP, whereas high CS levels induced by stress or GR agonist administration reduce it and attenuate memory (Diamond et al, 1992; Kerr et al, 1994).

On the other hand, CS plays a critical role in the acquisition and expression of behavioral strategies when animals are facing a particular aversive situation (Korte, 2001). For example, CS has been shown to facilitate the acquisition and retention of the immobility acquired in a forced-swim paradigm (de Kloet et al, 1988; Báez and Volosin, 1994). CS has also been implicated in the acquisition of inactivity during the exposure to inescapable shock (IS) and in the expression of inactivity and escape failures in a subsequent shuttle-box task (Báez et al, 1996). On the contrary, in nonstressed animals, CS reduced the possibility to develop learned helplessness (LH) and facilitated escape responses during the shuttle-box task (Edwards et al, 1990; Papolos et al, 1993; Báez et al, 1996; King et al, 2001).

The aim of the present study was to characterize the functional contribution of MR and GR in the LH paradigm. The effect of the administration of increasing doses of CS to adrenalectomize (ADX) animals was evaluated by measuring available cytosol receptor levels in order to define MR and GR involvement. The participation of each receptor subtype was also investigated by the infusion of the selective MR agonist - aldosterone (ALDO) - and the administration of CS associated to the GR antagonist, RU 38486.

\section{MATERIALS AND METHODS}

\section{Animals}

Adult (280-320 g body weight) male Wistar rats were housed in groups of three per cage. Food and water were available ad libitum. Animals were maintained on a $12 \mathrm{~h}$ light-dark cycle (lights on 0700-1900) and at a temperature of $21-23^{\circ} \mathrm{C}$. All the animals were allowed a week to habituate to the room before starting the experiments.

All the procedures were in agreement with the standards for care laboratory animals as outlined in the 'NIH Guide for the Care and Use of Laboratory Animals'. The local committee of ethics of the School of Chemical Sciences, National University of Córdoba, Córdoba, Argentina approved the experimental protocols.

\section{Adrenalectomy}

Bilateral adrenalectomy was performed in animals under deep anesthesia (Ketamine $(50 \mathrm{mg} / \mathrm{kg}) /$ xylazine $(10 \mathrm{mg} / \mathrm{kg})$ i.p.) by means of an aseptic surgical procedure.

In the three experiments that were conducted, the animals were submitted to adrenalectomy. Following surgery, a period of 3 days was left to allow the animals to recover. During this period, each animal was offered two bottles to drink: one containing saline solution $(0.9$ or $3 \%$ as indicated in each of the experiments performed) and the other tap water. Control rats underwent a sham surgery procedure, that is, adrenal glands were localized, manipulated but not extirpated.

Success of the adrenalectomy was confirmed by the determination of CS concentration in blood samples collected 18 or $20 \mathrm{~h}$ after surgery using the tail clip method (Spencer and McEwen, 1997). A small incision was made at the tip of the rat's tail to obtain the blood sample. For each sample, approximately $300 \mu \mathrm{l}$ of blood was collected in chilled dry tubes. An acrylic restrainer loosely held rats during blood sampling that lasted less than $90 \mathrm{~s}$, and animals were returned to their home cage afterwards. All the adrenalectomized animals used for the experiments had undetectable serum CS levels.

\section{Steroid Administration}

Drinking solutions of CS (Sigma) were prepared daily in $0.9 \%$ saline or tap water from a stock solution $(16.6 \mathrm{mg} / \mathrm{ml}$ in absolute ethanol) kept in a freezer at $-20^{\circ} \mathrm{C}$. The percentage of ethanol in each drinking solution was $2.4 \%$. The rats drink on average $0.72 \mathrm{ml}$ ethanol/day and mostly during the dark phase. This amount of alcohol does not interfere with the animal's behavior since it has cleared from circulation at the time of behavioral evaluation (JC Molina, personal communication).

The GR antagonist RU 38486 (kindly provided by Roussel-UCLAF, Romainville, France) was dissolved in propylene glycol and injected at a dose of $7.5 \mathrm{mg} / \mathrm{kg}$, s.c. This does was selected because it induces around $90 \%$ of GR occupancy when administered to ADX animals (Pavlides et al, 1995).

D-Aldosterone (Sigma) was dissolved in propylene glycol in a concentration of $1 \mathrm{mg} / \mathrm{ml}$. From this stock solution, a $0.125 \mu \mathrm{g} / \mu \mathrm{l}$ solution was prepared using the same vehicle to obtain the desired concentration of ALDO $(1 \mu \mathrm{g} / 100 \mathrm{~g}$ body weight/day), according to the mean fill volume and pumping rate of the mini-osmotic pumps. The solution was introduced into Alzet $2001^{\circledR}$ osmotic minipumps with an average pumping rate of $1 \mu \mathrm{l} / \mathrm{h}$ at $37^{\circ} \mathrm{C}$. The dose of ALDO used in this experiment was previously reported to restore salt appetite in ADX animals (McEwen et al, 1986), suggesting that ALDO at this dose has a functional effect on the brain. 


\section{Subcutaneous Implantation of Mini-Osmotic Pumps}

The osmotic pumps were implanted under the skin of the animal under a very short exposition to halothane anesthesia. After preparing the zone, a small incision was made in the skin between the scapulae. Using a hemostat, a small pocket was formed by spreading the subcutaneous connective tissues apart. The minipumps were placed under the skin with the flow moderator pointing away from the incision, which was closed with sutures.

\section{Stressors}

The animals were taken in their home cages to a separate experimental room where they were exposed to the electric footshock session. No other subjects were present in the experimental room during stress exposure. At the end of the stress session, rats were taken back to the initial room where they were kept until the shuttle-box task. This second test was performed in another experimental room, different from the one where inescapable footshock was delivered.

\section{Learned Helplessness Paradigm}

Inescapable shock. Animals were placed in a closed compartment $(30 \times 30 \times 30 \mathrm{~cm})$ of a standard automated box (Ugo Basile ${ }^{\circledR}$ ) where footshock was delivered through a stainless steel grid placed on the floor. In each IS session, 10 trials of shocks $(1 \mathrm{~mA})$ of $15 \mathrm{~s}$ duration at intervals of $30 \mathrm{~s}$ were applied. This shock regime was selected based on previous studies demonstrating that animals acquire behavioral inactivity following an initial period of activity (Murúa and Molina, 1991; Báez et al, 1996; Centeno and Volosin, 1997). Inactivity behavior involves the lack of any visible movement with the animals standing with all four paws on the floor. A trial was considered inactive when the animal remained motionless at least for $10 \mathrm{~s}$ during the $15 \mathrm{~s}$ shock delivery. The percentage of inactive trials was calculated over a total of 10 trials.

\section{Shuttle-Box Task}

Escape-avoidance behavior was evaluated in a standard two-way shuttle-box of $60 \times 30 \times 30 \mathrm{~cm}$ built with Plexiglas walls and stainless steel rods on the floor separated from each other by a distance of $1 \mathrm{~cm}$. A wood divider placed in the middle of the box separated two equal-sized compartments. An acoustic signal (conditioned stimuli) was given during the first $5 \mathrm{~s}$ of each trial before the footshock administration; if no response occurred within this period, a $1 \mathrm{~mA}$ shock $(15 \mathrm{~s} / 30 \mathrm{~s})$ was applied. A total of 30 trials were performed and the number of escape failures - noncrossing response during the shock application-was registered. A shuttle-box trial was considered inactive when the animals remained inactive for at least $10 \mathrm{~s}$. The percentage of escape failures was calculated over a total of 30 trials.

The boxes where the stressor was administered were carefully cleaned between each animal evaluation. A person blind to the treatment and experimental condition of each animal did the behavioral evaluations.

\section{Specific Cytosol Receptor Binding Assays}

The particular features of specific binding assays for corticosteroid receptors, as described by Spencer et al (1990), permit evaluation of the levels of activation or occupancy of such sites at any central nervous system region dissected. Cytosol MR and GR binding normalized to protein (MR and GR binding density) was determined in ADX animals with or without CS replacement and in SHAM rats under the same experimental conditions. From the relation among these measures, the 'apparent cytosol receptor depletion (ACRD)' was estimated based on the assumption that the levels of available cytosolic receptors determined in the ADX condition stand for $100 \%$ of the receptors population. MR and GR binding density was determined in cytosolic samples on hippocampus tissue from individual intact and ADX animals using saturation binding assays.

The saturating concentrations of the radiolabeled ligands used herein (dexamethasone- ${ }^{3} \mathrm{H}$ and aldosterone- ${ }^{3} \mathrm{H}$ ) were selected from preliminary specific binding assays. In order to standardize the protocols incubating conditions, saturation curves were obtained using increasing concentrations of radioligand. $B_{\max }$ and $K_{\mathrm{d}}$ values were estimated in rat hippocampus pools by means of Scatchard analyses. The results (data not shown) were consistent with those from literature where similar incubation conditions were used.

\section{MR Determination}

MR were estimated as the difference between total binding to aldosterone- ${ }^{3} \mathrm{H} \quad(10 \mathrm{nM}) \quad\left(\mathrm{NET}-419, \quad \mathrm{D}-\left[1,2,6,7-{ }^{3} \mathrm{H}(\mathrm{N})\right.\right.$ aldosterone- $-76.4 \mathrm{Ci} / \mathrm{mmol}, \mathrm{NEN}^{\mathrm{TM}}$ Life Science Products Inc.) in the presence of 100 -fold of the selective GR agonist RU 28362 (Roussel-Uclaf, Romainville, France). Nonspecific binding was determined in the presence of cold CS (5000 nM).

\section{GR Determination}

GR were estimated as the difference among total binding to dexamethasone- ${ }^{3} \mathrm{H}(20 \mathrm{nM})\left(\mathrm{NET} 467\left[6,7-{ }^{3} \mathrm{H}(\mathrm{N})\right]\right.$ dexamethasone, $40.0 \mathrm{Ci} / \mathrm{mmol}$, PerkinElmer ${ }^{\mathrm{TM}}$ Life Sciences) and binding in the presence of 250 -fold of the selective GR agonist RU 28362 (Roussel-Uclaf, Romainville, France).

\section{Tissue Sample Dissection}

Animals were killed by decapitation (between 0800 and 1000). Brains were removed immediately and dissected on ice to yield the hippocampus according to the method of Heffner et al (1980). The regions were snap frozen on dry ice and stored at $-70^{\circ} \mathrm{C}$ until the assays were performed.

\section{Procedure}

Each hippocampus was homogenized in TEMGD buffer (10 mM Tris, $1 \mathrm{mM}$ EDTA, $20 \mathrm{mM}$ sodium molybdate, $5 \mathrm{mM}$ dithiothreitol, and $10 \%$ glycerol in double-distilled water, $\mathrm{pH} 7.4 ; 15-20$ strokes) in a proportion of $100 \mathrm{mg}$ tissue/ $700 \mu \mathrm{l}$ buffer and centrifuged at $105000 \mathrm{~g}$ for $60 \mathrm{~min}$ at $4{ }^{\circ} \mathrm{C}$. The supernatant or cytosol was added to the incubation 
solutions containing the radiolabeled steroid with or without the cold ligand. Samples were incubated at $4^{\circ} \mathrm{C}$. during 18-22 h. Sephadex LH-20 (Sigma ${ }^{\circledR}$ ) columns were used to separate bound from free steroid. Eluates containing the bound fraction were collected into scintillation vials. Radioactivity was measured in a liquid scintillation counter (Beckman $^{\circledR}, 35 \%$ efficiency).

\section{Proteins}

Protein concentrations in the cytosolic fractions were determined by the method of Bradford (using a commercial BioRad ${ }^{\circledR}$ kit) using bovine serum albumin as the standard. The concentration of proteins was adjusted in the range of $0.5-1.5 \mathrm{mg}$ of protein $/ \mathrm{ml}$ of cytosol.

\section{Serum CS Assay}

Blood samples were centrifuged $\left(4^{\circ} \mathrm{C}\right)$ for $10 \mathrm{~min}$ at $3000 \mathrm{rpm}$. Serum was separated immediately afterwards and stored at $-30^{\circ} \mathrm{C}$. Serum CS was assessed in duplicate by a modified competitive protein binding assay (Murphy, 1967). Briefly, $25 \mu \mathrm{l}$ serum and $75 \mu \mathrm{l}$ distilled water were placed in boiling water for $90 \mathrm{~s}$; after cooling, samples were incubated with a corticosteroid binding globulin tracer solution ( $2 \%$ horse serum containing $1,2,6,7-{ }^{3} \mathrm{H}$-corticosterone ( $88 \mathrm{Ci} / \mathrm{nmol}$; NEN Chemicals) as tracer). Unbound steroid was removed using Florisil (mesh 60-100, Sigma). Standard CS was supplied by Sigma. The serum CS concentrations are expressed in terms of $\mu \mathrm{g} / \mathrm{dl}$. The sensitivity of the method was $0.5 \mathrm{ng}$ of CS. The intra- and interassay coefficients of variation were lower than $7 \%$.

\section{Experimental Designs}

Experiment 1: Effects of CS administration on behavioral deficits induced by IS. This experiment was devised to evaluate the effects of the administration of increasing doses of CS to ADX rats on inactivity behavior and escape failures during IS and shuttle-box task.

Following a recovery period of 3 days after adrenalectomy, animals were randomly assigned to the different experimental groups and they received two drinking bottles both containing CS solutions (saline solution or tap water) at a given dose until the end of the experiment. According to the dose of CS administered, the following experimental groups were formed: ADX rats without hormone replacement and receiving vehicle $(\mathrm{ADX}-\mathrm{VEH})$ and $\mathrm{ADX}$ animals with the following doses of CS: $20 \mu \mathrm{g} / \mathrm{ml}$ (CS 20), $50 \mu \mathrm{g} / \mathrm{ml}$ (CS 50), $100 \mu \mathrm{g} / \mathrm{ml}$ (CS 100), $200 \mu \mathrm{g} / \mathrm{ml}$ (CS 200), and $400 \mu \mathrm{g} / \mathrm{ml}$ (CS 400). An additional group of sham-operated rats that received vehicle treatment was included (SHAM$\mathrm{VEH}$ ). SHAM-VEH rats were given the saline and tap water solutions containing $2.4 \%$ ethanol, respectively.

The beginning of the hormone replacement was considered as the first day of the experiment (ie Day 1). Animals were exposed to IS on Day 2 and the shuttle-box task was performed $48 \mathrm{~h}$ later (ie Day 4). Therefore, the hormone replacement treatment took place for three consecutive days (Day 1 to Day 4). All experiments were performed during the light cycle, between 0900 and 1200 .
The drinking bottles containing CS solution were removed from the animal cages immediately before the 30-min shuttle-box task. At 10 min after the completion of the task, animals were killed, hippocampi were dissected for the binding assays, and trunk blood was collected for serum CS analysis. Hence, the total time elapsed between the removal of the drinking solutions containing CS and the blood collection for the analysis of CS levels was approximately $40 \mathrm{~min}$ in average.

Basal CS levels were assessed in blood samples collected just prior to stress exposure from sham-operated controls, using the tail clip method.

Experiment 2: Effect of GR blockade on behavioral deficits induced by IS. This experiment was conceived to evaluate the behavioral effects mediated putatively by MR activation alone. The pharmacological approach consisted in the selective blockade of GR with RU 38486 to permit only the access of CS to MR. For this study, the $100 \mu \mathrm{g} / \mathrm{ml}$ dose of CS was selected since it induced a high degree of reduction of available MR accompanied by moderate reduction of available GR.

As in Experiment 1, ADX rats were treated with CS or VEH from Day 1 until Day 4. IS session took place on Day 2 and the shuttle-box task on Day 4. The animals that were administered with RU 38466 received two subcutaneous injections: one was given $2 \mathrm{~h}$ before IS and the other $2 \mathrm{~h}$ before shuttle-box testing. Therefore, the following four experimental groups of ADX rats were constituted: $\mathrm{VEH}$; RU 38486; CS 100; CS 100 + RU 38486.

Experiment 3: Effect of ALDO on the behavioral deficits produced by IS. The purpose of the third experiment was to investigate the effect of a selective MR activation on inactivity behavior during the IS session and on escape failures during the shuttle-box task, using ALDO as a specific agonist. After ADX, rats were placed in cages equipped with two bottles: one containing a $3 \%$ sodium chloride solution and the other tap water. The 3\% sodium chloride solution allowed a better discrimination of saline $v s$ water preference among intact and ADX animals than a solution of lower concentration of sodium chloride $(0.9 \%)$. Graduated bottles facilitated the monitoring of the liquid ingested that was registered in milliliter. ADX rats showed a greater saline appetite with an increase in the consumption of saline of around 12-14 ml/day as compared to intact rats that ingested $3 \mathrm{ml}$ in average. This last control was only performed to set and monitor the mean drink ingestion in each case.

The osmotic minipumps containing ALDO $(1 \mu \mathrm{g} / 100 \mathrm{~g}$ body weight/day) were implanted 3 days after adrenalectomy between 0800 and $1000 \mathrm{~h}$ (ie on Day 1). The animals were exposed to IS on Day 2, $24 \mathrm{~h}$ after the implantation of the minipumps, which were maintained until the end of the shuttle-box task (ie on Day 4). Hence, the treatment with ALDO was performed for 3 consecutive days - for a length of time similar to that with CS.

Control ADX rats were implanted with minipumps filled with $\mathrm{VEH}$ and received the water $/ 3 \%$ saline alternative to drink. Thus, two experimental groups of ADX rats were conformed: VEH and ALDO. 


\section{Statistical Analyses}

Results are expressed as mean \pm SEM. Data were analyzed by using one- or two-way analysis of variance (ANOVA) according to the factors introduced in the experimental design. Where $\mathrm{F}$ ratios were significant, post hoc comparisons were made using Newman-Keuls test. Significance levels were set at $p<0.05$.

\section{RESULTS}

\section{Experiment 1}

Table 1 shows the percentage of inactive trials during IS exposure of ADX animals with and without CS replacement. ANOVA revealed significant differences among the experimental groups $(\mathrm{F}(6,55)=8.06, p<0.01)$. Subsequently, post hoc comparisons indicated that ADX-VEH and SHAM rats performed a high percentage of inactive trials, whereas ADX rats treated with 20,50 , or $100 \mu \mathrm{g} / \mathrm{ml}$ of CS exhibited a clearcut drop in inactivity during IS compared with both groups.

The percentage of inactive trials of ADX rats replaced with $200 \mu \mathrm{g} / \mathrm{ml}$ of CS was comparable to that in ADX-VEH and SHAM groups. As for the CS 400 dose, the percentage of inactive trials was lower than for the ADX-VEH and SHAM groups and indeed significantly lower than the percentage of inactive trials of CS 200 group.

The effects of CS replacement on escape failures in ISexposed ADX rats are shown in Figure 1. As for the percentage of escape failures in the active avoidance task, the one-way ANOVA indicated a significant effect of treatment $(\mathrm{F}(6,56)=6.37, p<0.01)$. ADX rats treated with VEH displayed high percentage of escape failures. As expected, the same effect was observed in SHAM rats. This behavioral deficit decreased in ADX animals substituted with 20 and $50 \mu \mathrm{g} / \mathrm{ml}$ of CS. Both groups showed a significantly lower percentage of escape failures than the ADX-VEH group. This CS effect was greater after the replacement with the $100 \mu \mathrm{g} / \mathrm{ml} \mathrm{CS}$ dose. In fact, post hoc analysis revealed that the CS 100 group showed a lower percentage of escape failures as compared to the CS 20 and CS 50 groups, and also lower than the rest of the experimental groups (ADX, SHAM, CS 200, and CS 400). Besides, no significant differences were observed in the pattern of behavioral deficits between ADX rats replaced with the 200 or $400 \mu \mathrm{g} / \mathrm{ml}$ CS dose and SHAM and ADXVEH groups.

According to their affinity for CS and the doses administered, the available cytosolic levels of MR and GR were determined in the SHAM, ADX, CS 20, CS 50, CS 100, and CS 400 groups. These determinations were performed on hippocampal tissue belonging to the same animals used for the behavioral assessments described above. The results of the percentages of MR and GR ACRD are shown in Figure 2 .

The corresponding ANOVAs revealed a significant effect of treatment for MR $(F(4,15)=3.6, p<0.05)$ and GR $(F(4$, $15)=209.6, p<0.01)$ ACRD percentages. Subsequent post hoc analyses revealed that in the CS 20 group the percentage of MR ACRD was significantly lower as compared to the MR ACRD of all the other animal groups. Concerning GR, there
Table I Inactivity During IS Exposure

\begin{tabular}{ll}
\hline SHAM & $53.6 \pm 5.1 \%$ \\
ADX- VEH & $50.3 \pm 6.3 \%$ \\
ADX+CS 20 & $28.3 \pm 5.2 \% *$ \\
ADX+CS 50 & $20.0 \pm 2.4 \% *$ \\
ADX+CS 100 & $22.5 \pm 4.4 \% *$ \\
ADX+CS 200 & $56.7 \pm 4.1 \%$ \\
ADX+CS 400 & $31.6 \pm 4.7 \% *$
\end{tabular}

*p $<0.05$ vs ADX-VEH, SHAM, and CS 200 (Newman-Keuls test)

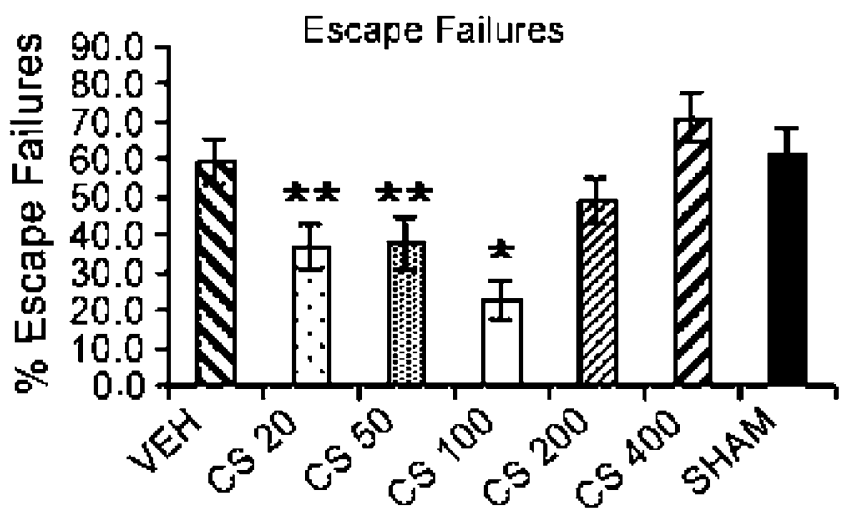

Figure I Behavioral effect of adrenalectomy and CS replacement in stressed animals. The percentage of escape failures in a shuttle-box task carried out $48 \mathrm{~h}$ after IS exposure is represented. Results are expressed as mean \pm SEM $(n=8-9$ in each case). $* p<0.0$ I compared with the rest of the groups, *** $<0.05$ compared with VEH and CS I00 (Newman-Keuls test).

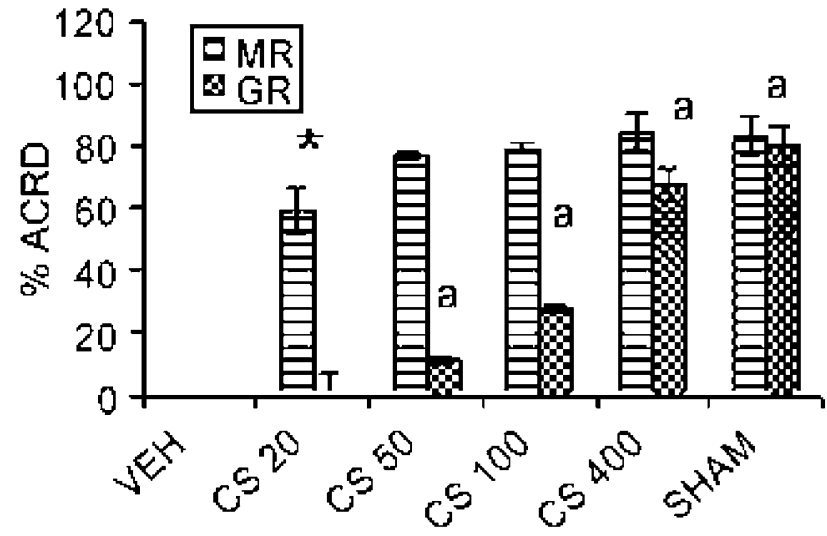

Figure 2 Pattern of hippocampal MR and GR ACRD after the shuttlebox task in SHAM and ADX animals replaced with the different doses of CS. The percentage of ACRD was estimated based on the assumption that the levels of available cytosolic receptors determined in the ADX condition stand for $100 \%$ of the receptors population. Each value represents the mean \pm SEM ( $n=5-6$ in each case). $* p<0.05$ compared to MR ACRD from the rest of the groups, ${ }^{a} p<0.05$ vs GR ACRD in the rest of the groups (Newman-Keuls test).

was a significant and progressive increase in the ACRD according to the CS dose administered. In other words, the lowest ACRD took place with $20 \mu \mathrm{g} / \mathrm{ml}$ CS dose; meanwhile 
the highest CS dose $(400 \mu \mathrm{g} / \mathrm{ml})$ produced a percentage of GR ACRD similar to that in intact rats. The overall analysis of the data revealed that the percentages of MR and GR ACRD corresponding to SHAM animals (80\% GR and $90 \%$ MR) were similar to those of the CS 400 group (70\% GR and $100 \% \mathrm{MR})$, without significant differences between them.

Serum basal CS levels obtained just prior to stress exposure from sham-operated controls $(n=8)$ averaged $2.5 \pm 0.8 \mu \mathrm{g} / \mathrm{dl}$ samples. All of the ADX animals - treated with VEH and regardless of the CS replacement treatment received - had undetectable levels of serum CS before the behavioral evaluation was performed. This aspect will be discussed below in relation to the interpretation of the percentages of ACRD.

\section{Experiment 2}

This experiment was designed to evaluate the effect of GR blockade on the behavioral changes induced by CS administration in IS-exposed ADX rats. Based upon the results obtained in the previous experiment, we selected the $100 \mu \mathrm{g} / \mathrm{ml}$ CS dose, which induced a remarkable reduction in the inactivity produced by IS and in the subsequent escape failures during the shuttle-box task. Thus, the percentage of inactive trials and escape failures of ISexposed ADX rats treated with the specific GR antagonist RU 38486 and $100 \mu \mathrm{g} / \mathrm{ml}$ of CS were analyzed.

Table 2 shows the percentage of inactive trials during IS. ANOVA revealed a significant interaction between the factors 'CS replacement' and 'treatment' $(\mathrm{F}(3,28)=7.6$, $p<0.01)$. Post hoc analysis revealed that the ADX + CS 100 group showed a lower percentage of inactive trials than $\mathrm{ADX}-\mathrm{VEH}$ rats, reproducing the results from the previous experiment. Also, the percentage of inactive trials of the $\mathrm{ADX}+\mathrm{CS} 100+\mathrm{RU} 38486$ group was not significantly different from the ADX + CS 100 and ADX + VEH groups but corresponded to intermediate values among the latest two groups, whose percentages of inactive trials were statistically different. There was no significant effect following the administration of RU 38486 by itself.

The two-way ANOVA applied to analyze the behavioral recordings (percentage of escape failures) in the shuttle-box task showed a significant interaction between the factors ' $\mathrm{CS}$ replacement' and 'treatment' $(\mathrm{F}(1,14)=20.89, p<0.01)$. As depicted in Figure 3, the percentage of escape failures from the ADX + CS 100 groups was significantly lower than the $\mathrm{ADX}+\mathrm{VEH}$ and ADX + RU 38486 groups. However, the treatment with RU 38486 reversed the effect of CS replacement. In fact, the percentage of escape failures was significantly higher in the ADX + CS $100+$ RU 38486 group as compared to the ADX + CS 100 group and similar to ADX-VEH group.

\section{Experiment 3}

In contrast to CS treatment, ALDO administration to ADX rats had no effect on LH behavior. No significant differences were observed in any of the evaluated parameters - namely, the percentage of inactive trials displayed during IS exposure and the behavioral performance during the shuttle-box task-between ADX rats treated with VEH and those treated with ALDO (data not shown).
Table 2 Inactivity During IS Exposure

\begin{tabular}{ll}
\hline$A D X+V E H$ & $50.3 \pm 6.3 \%$ \\
$A D X+R \cup 38486$ & $65.0 \pm 2.9 \%$ \\
$A D X+C S 100$ & $22.5 \pm 4.4 \% *$ \\
$A D X+C S 100+R \cup 38486$ & $38.8 \pm 8.7 \% * *$ \\
\hline
\end{tabular}

* $p<0.05$ compared with ADX+VEH and ADX+RU 38486, ** $p<0.05$ compared with $A D X+R \cup 38486$ (Newman-Keuls) $n=8$ in each case.

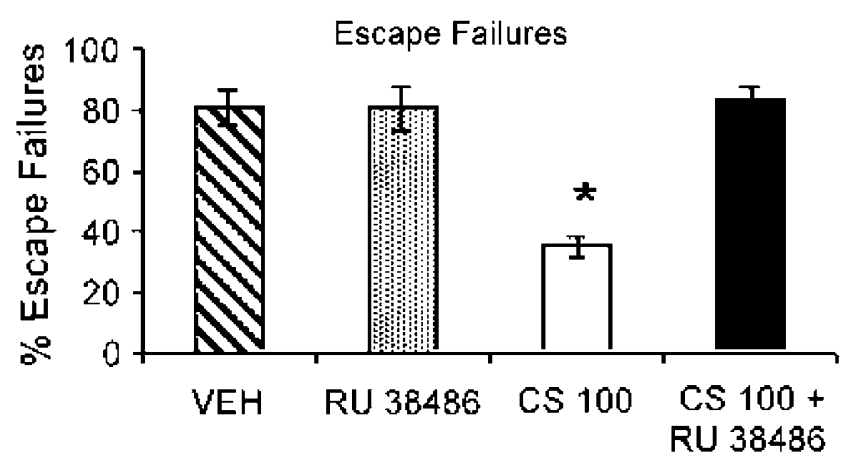

Figure 3 Effect of RU 38486 administration on escape failures in ADX rats replaced with $C S$. The percentage of escape failures in the shuttle-box task performed $48 \mathrm{~h}$ post-IS is represented. The GR antagonist was administered $2 \mathrm{~h}$ before $\mathrm{IS}$ and $2 \mathrm{~h}$ before shuttle-box task. Each value represents the mean $\pm \operatorname{SEM}(n=4$ in each case). $* 0<0.01$ vs the rest of the groups (Newman-Keuls test).

\section{DISCUSSION}

The studies described in this paper demonstrate that ADX Wistar rats treated with VEH acquired and express LH behavior at a level similar to SHAM animals with their adrenals in place. A novel finding in the present study is that ADX rats treated with moderate levels of CS that deplete MR and some GR reduce LH markedly, whereas replacement with high doses of CS, which more fully deplete GR, return LH to the high levels seen in both ADX SHAM rats. It should be noted that the available MR and GR levels are measured right after behavioral tests and reflect the level of receptor depletion at the time the behavior is assessed, even though blood levels of CS are undetectable at the time of behavioral testing. The effects on LH behavior are reminiscent of a $U$-shaped dose-response curve that has been found for neuronal excitability in the hippocampus.

\section{Measurement and Meaning of ACRD}

This study links available cytosol MR and GR levels with behavior, reflecting MR and GR availability in the cytosol. Blood levels of CS at the time of killing, right after the behavioral tests, were very low, indicating that there was no exogenous CS present at the time of the IS/SB exposure events. This is due to the fact that CS consumed the night before in the drinking water are cleared from the blood when the animals enter the light phase of their cycle when they are drinking less.

We found that, at a CS dose of $400 \mu \mathrm{g} / \mathrm{ml}$, the ACRD for MR is almost complete and GR is depleted by $70 \%$, which is 
comparable to the SHAM group (90 and $80 \%$, respectively). In both cases, the animals expressed a similar pattern of behavioral alterations during the active avoidance testing. Hence, these results lead to the important conclusion that the maintenance of active escape behavior requires the cytosolic depletion of virtually all MR and some GR, whereas the depletion of a high percentage of GR (as may occur in stress) reinstates passive (ie LH) behavior.

Concerning the measure of 'ACRD', it is important to note that the present studies, which compare available receptor binding levels in $\mathrm{ADX}$ rats with and without $\mathrm{CS}$ replacement, make the assumption that there are no differences between the various treatments in total receptor expression. However, because measurement of receptor occupancy is limited by the inability of the binding assay to measure total receptor levels in the presence of circulating hormone, ADX has been used to estimate total available receptors.

A possibility that cannot be ruled out is that the CS exposure as well as the clearance of endogenous corticosteroids impacts on receptor protein expression. Therefore, and based on recent findings (Spencer et al, 2000; Kalman and Spencer, 2002), it is possible that MR and/or GR levels may have been affected by the hormone manipulations, including the exposure to different doses of CS.

Another aspect of the measurement of MR and GR levels is the clearance of CS from the blood and from the receptors. As noted above, at the time of receptor binding assays, blood levels of CS were almost undetectable, indicating rapid clearance of CS from the blood. Because CS appears to clear rapidly from receptors, within several hours after maximum receptor occupancy (Hache et al, 1999; Kitchener et al, 2004), the measures of MR and GR ACRD may represent either: (1) receptor levels that have been downregulated by prior CS exposure or (2) receptor levels that have not yet recovered due to a lag in receptor recycling. Future studies will need to use alternative experimental approaches, such as Western blotting of total receptor protein, which were beyond the scope of the present investigation. Nevertheless, the reported ACRD is a measure of prior CS exposure and is more reflective of the effect of CS on the brain than is the blood level of CS, and the reported levels of receptor depletion are related to different expressions of active avoidance and LH behavior.

\section{Possible Strain Differences in LH Susceptibility}

The high expression of LH in ADX animals was originally reported in rats of the Sprague-Dawley strain, and it is important to note that $\mathrm{ADX}$ rats in those studies showed a greater vulnerability to develop the LH behavior compared to animals with intact adrenals (Edwards et al, 1990; King et al, 1993). In the current study, we found in Wistar rats a high proportion of both SHAM and ADX animals that acquire and express the behavioral deficits (SHAM 83\% vs ADX $82 \%$ ), but it is conceivable that, with a shorter duration of IS exposure (Murúa and Molina, 1991), we might have been able to show a further increase in $\mathrm{LH}$ after ADX. This possibility remains to be tested. Nonetheless, it is possible that intact animals from the Wistar strain, in contrast to Sprague-Dawley rats, possess inherent differences, both in the vulnerability to develop alterations in the behavioral performance, and in the basal and stress-induced activity of the hypothalamic-pituitary-adrenal axis and/or the sensitivity to CS.

\section{Relationship to LH Expression to Apparent MR and GR Depletion}

An analysis of MR and GR ACRD from SHAM animals and ADX animals replaced with different doses of CS allowed us to establish a more exact relationship with the $\mathrm{LH}$ behavior. At low doses of $\mathrm{CS}$ in the $20-50 \mu \mathrm{g} / \mathrm{ml}$ range and at an intermediate dose of $100 \mu \mathrm{g} / \mathrm{ml}$, ADX rats displayed few behavioral deficits such as low scores of inactivity and escape failures. At the $20 \mu \mathrm{g} / \mathrm{ml} \mathrm{CS}$ dose, there was low MR depletion that increased markedly with the intermediate dose (CS 100) at which there was some GR depletion. In fact, animals replaced with $100 \mu \mathrm{g} / \mathrm{ml}$ of CS showed such low level of inactivity and escape deficits that we conclude that a fully stimulated MR system plus a partially depleted GR system corresponds to the most adequate and optimal condition to impede the acquisition and later expression of the behavioral impairments induced by IS.

These findings confirm previous results that pointed indirectly to the same effect for endogenously released CS, since giving rats metyrapone before IS to inhibit CS synthesis and abolish the stress-induced CS peak prevented LH behavior induced by IS (Báez et al, 1996). Interestingly, following the administration of metyrapone, CS levels are maintained around $10 \mu \mathrm{g} / \mathrm{dl}$, indicating that most of MRs and part of GRs should be occupied, and the animals showed few escape failures, similar to the CS 100 group in the present report.

In contrast, high doses of CS would be associated with a greater capacity to express behavioral deficits, as it was observed in ADX animals that received 200 or $400 \mu \mathrm{g} / \mathrm{ml}$ of CS. These results are consistent with previous work from our laboratory (Báez et al, 1996) that demonstrated in Wistar rats that IS-exposed rats treated with metyrapone and then supplemented with high doses of CS or dexamethasone displayed a high percentage of escape failures during the active avoidance testing.

As it has been shown in other studies (Murúa and Molina, 1991; Báez et al, 1996; Centeno and Volosin, 1997), inactivity during IS and behavioral deficits during shuttlebox task are related. Moreover, glucocorticoids are functionally involved in the inactivity induced by IS, which leads to the behavioral expression observed later during the shuttle-box task. However, although the administration of CS at $200 \mu \mathrm{g} / \mathrm{ml}$ facilitated $\mathrm{LH}$, we found that the administration of a higher dose - CS 400 - was associated with a somewhat lower percentage of inactivity during IS exposure, whereas these same animals manifested a high percentage of escape failures in the shuttle-box task. This discrepancy requires a more exhaustive investigation but does not detract from the main findings of the study.

\section{The U-Shaped Dose-Response Cruve and Possible Explanations}

CS has a wide range of regulatory effects on brain function. Some of them rely on tonic (permissive or proactive) effects of the hormone, whereas others are due to the dynamic 
actions of stress-induced phasic increases in corticosteroid secretion (de Kloet et al, 1998). Our estimates of ACRD, which are subject to several uncertainties that are outlined above, are relative measures of CS exposure. What these estimates point to is that CS exposure and activation of MR and GR produce effects on the brain that result in altered escape behavior in the $\mathrm{LH}$ paradigm. These effects may involve alterations in neuronal excitability such as have been described for serotoninergic, cholinergic, glutamatergic, and noradrenergic function in hippocampus (Joels and de Kloet, 1992) and for LTP and long-term depression (see below). The basic rule appears to be that low-to-moderate levels of MR occupancy and increasing levels of GR activation gradually shift each of these endpoints in a Ushaped or inverted U-shaped pattern.

High levels of GR ACRD are associated with a reversal of the suppression and an enhancement of LH. It is possible that the rat strain differences (see Discussion) may be related either to CS serum concentration or to the level of expression of GR.

Intermediate GR ACRD induces suppression of $\mathrm{LH}$ behavior, while either very low or very high GR ACRD is associated with LH behavior. These findings could be related to the inverted ' $U$ ' function that has been described in electrophysiology among the levels of CS and the primed burst potentiation (PBP) and LTP phenomena (Diamond et al, 1992; Kerr et al, 1994; Pavlides et al, 1995), in which intermediate concentrations of CS in plasma $(10-20 \mu \mathrm{g} / \mathrm{dl})$ yielded a peak potentiation, and $M R$ and some GR occupancy appears to be related to optimal performance.

However, although there exists a similarity in the behavioral performance of the ADX-VEH and the SHAM and $\mathrm{ADX}+\mathrm{CS} 400$ groups, there are likely to be other factors that contribute to the two extreme arms of the ' $U$ '. It is conceivable that the elevation of $\mathrm{LH}$ in either or both ADX and SHAM animals could be mediated by changes in central CRH activity (Dunn and Berridge, 1990; Owens and Nemeroff, 1991). This hyothesis is supported by the observations of Takamori et al (2001), who demonstrated that the administration of specific antagonists of CRF receptor subtype 1 (CRF1) in the behavior acquisition phase, that is, $60 \mathrm{~min}$ before IS, reduced the number of escape failures.

Finally, as the lowest dose of CS, ALDO administered to ADX rats showed that MR occupancy alone is not sufficient to block the onset and expression of the behavioral deficits induced by IS exposure. The dose of ALDO used in this experiment was previously reported to restore salt appetite in ADX animals (McEwen et al, 1986), suggesting that ALDO at that dose has a functional effect on the brain. Rather, some GR occupancy is required, as indicated by the fact that giving the GR antagonist RU 38486 to ADX rats that received $100 \mu \mathrm{g} / \mathrm{ml}$ of CS prevented the suppression of LH behavior seen at that dose. Future studies should investigate the transition between $M R$ and $M R+G R$ occupancy using combined treatments with ALDO and a specific GR agonist, such as RU 28362.

In conclusion, CS levels that produce a high percentage of MR depletion associated with a modest GR depletion are necessary to avoid the instatement of behavioral impairments in stressed animals, and thus suppress $\mathrm{LH}$ behavior. High levels of GR depletion are associated with a reversal of the suppression and an enhancement of $\mathrm{LH}$.

\section{ACKNOWLEDGEMENTS}

Grants from CONICET 0679/98, SECyT-UNC 194/00, and FONCyT-ACC 05-0741/99 to M Volosin (ARGENTINA) and MH 41256 and 5P50MH58911 NIH grants to BS McEwen (USA) supported this work. We thank Miss Elsa Pereyra and Mrs Estela Salde for their skillful technical assistance and Mrs Adelaide Acquaviva for her assistance in editing this article.

\section{REFERENCES}

Ahima RS, Harlan RE (1990). Charting of type II glucocorticoid receptor-like immunoreactivity in the rat central nervous system. Neuroscience 39: 579-604.

Ahima R, Krozowski Z, Harlan R (1991). Type I corticosteroid receptor-like immunoreactivity in the rat CNS: distribution and regulation by corticosteroids. J Comp Neurol 313: 522-538.

Báez M, Siriczman I, Volosin M (1996). Corticosterone is involved in foot shock-induced inactivity in rats. Phyio Behav 60: 795-801.

Báez M, Volosin M (1994). Corticosterone influences forced-swim induced immobility. Pharmacol Biochem Behav 49: 729-736.

Calvo N, Martijena I, Molina V, Volosin M (1998). Metirapone pretratment prevents the behavioural and neurochemical sequelae induced by stress. Brain Res 800: 227-235.

Calvo N, Volosin M (2001). Glucocorticoid (GR) and mineralcorticoid (MR) receptors are involved in the facilitation of anxietylike response induced by restraint. Neuroendocrinology 73: 261-271.

Centeno V, Volosin M (1997). Chronic treatment with desipramine: effect on endocrine and behavioral responses induced by inescapable stress. Physiol Behav 62: 939-944.

Dallman MF, Akana SF, Scribner KA, Bradbury MJ, Walker CD, Strack AM et al (1992). Stress, feedback and facilitation in the hypothalamic-pituitary-adrenal axis. J Neuroendocrinol 4: 517-526.

De Kloet ER, De Kock S, Schild V, Veldhuis HD (1988). Antiglucocorticoid RU 38346 attenuates retention of a behavior and disinhibits the hypothalamic-pituitary-adrenal axis at different brain sites. Neuroendocrinology 47: 109-115.

De Kloet ER, Oitzl MS, Joels M (1999). Stress and cognition: are corticosteroids good or bad guys? Trends Neurosci 22: 422-426.

De Kloet ER, Vreugdenhil E, Oitzl MS, Joels M (1998). Brain corticosteroid receptors balance in health and disease. Endocrine Rev 19: 269-301.

De Quervain DJF, Roozendaal B, Nitsch RM, McGaugh JL, Hock C (2000). Acute cortisome administration impairs retrieval of longterm declarative memory in humans. Nat Neurosci 3: 313-314.

Diamond DM, Bennett MC, Fleshner M, Rose GM (1992). Inverted $\mathrm{U}$ relationship between the levels of peripheral corticosterone and the magnitutde of hippocampal primed burst potentiation. Hippocampus 2: 421-430.

Diamond DM, Ingersoll N, Branch BJ, Mesches MH, ColemanMesches K, Fleshner M (1998). Stress impairs cognitive and electrophysiological measures of hippocampal function. In: Levy A, Grauer E, Ben-Nathan D, de Kloet ER (eds). New Frontiers in Stress Research: Modulation of Brain Function. Harwood Academic Publishers: Amsterdam. pp 117-126.

Dunn AJ, Berridge CW (1990). Physiological and behavioural responses to corticotropin-releasing factor administration: is CRF a mediator of anxiety or stress responses? Brain Res Rev 15: 71-100. 
Edwards E, Harkins H, Wright G, Henn FA (1990). Effects of bilateral adrenalectomy on the induction of learned helplessness behavior. Neuropsychopharmacology 3: 109-114.

Hache RJ, Tse R, Reich T, Savory JG, Lefebvre YA (1999). Nucleocytoplasmic trafficking of steroid-free glucocorticoid receptor. J Bio Chem 274: 1432-1439.

Heffner TG, Hartman JA, Seiden LS (1980). A rapid method for the regional dissection of the rat brain. Pharmacol Biochem Behav 13: $453-456$.

Joels M, de Kloet ER (1992). Control of neuronal excitability by corticosteroid hormones. Trends Neurosci 15: 25-30.

Joels M, Werkman T, Karst H, Juta TJA, Wadman W (1998). Corticosteroids and calcium homeostasis: implication for neuroprotection and neurodegeneration. In: Levy A, Grauer E, BenNathan D, de Kloet ER (eds). New Frontiers in Stress Research: Modulation of Brain Function, 40th Oholo Conference. Hardwood Academic Publishers: Newark, NJ. pp 95-104.

Kalman BA, Spencer RL (2002). Brain corticosteroid dependent regulation of mineralocorticoid receptor protein expression in rat brain. Endocrinology 143: 4184-4195.

Kerr DS, Huggett AM, Abraham WC (1994). Modulation of hippocampal long-term potentiation and long-term depression by corticosteroid receptor activation. Psychobiology 22: 123-133.

King JA, Abend S, Edwards E (2001). Genetic predisposition and the development of posttraumatic stress disorder in an animal model. Biol Psychiatry 50: 231-237.

King JA, Campbell D, Edwards E (1993). Differential development of the stress response in congenital learned helplessness. Int $J$ Dev. Neurosci 11: 435-442.

Kitchener P, Di Blasi F, Borrelli E, Piazza PV (2004). Differences between brain structures in nuclear translocation and DNA binding of the glucocorticoid receptor during stress and the circadian cycle. Eur J Neurosci 19: 1837-1846.

Korte SM (2001). Corticosteroids in relation to fear, anxiety and psychopathology. Neurosci Biobehav Rev 25: 117-142.

Lupien SJ, McEwen BS (1997). The acute effects of corticosteroids on cognition: integration of animal and human model studies. Brain Res Rev 24: 1-27.

McEwen BS, Lambdin LT, Rainbow TC, De Nicola AF (1986). Aldosterone effects on salt appetite in adrenalectomized rats. Neuroendocrinology 43: 38-43.

Murphy BEP (1967). Some studies of the protein-binding steroids and their application to the routine micro- and ultramicro measurement of various steroids in body fluids by competitive protein-binding radio assay. J Clin Endocrinol Metab 27: 973-983.
Murúa SA, Molina VA (1991). Antidepressants reduce inactivity during both inescapable shock administration and shuttle box testing. Eur J Pharmacol 204: 187-192.

Oitzl MS, de Kloet ER (1992). Selective corticosteroid antagonists modulate specific aspects of spatial orientation learning. Behav Neurosci 106: 62-71.

Oitzl MS (1998). Brain corticosteroid receptors: behavioral and neuroendocrine aspects. In: Levy A, Grauer E, Ben-Nathan D, de Kloet ER (eds). New Frontiers in Stress research: Modulation of Brain Function. Hardwood Academic Publishers: Newark, NJ. pp 45-52.

Oitzl MS, Reichardt HM, Joels M, de Kloet ER (2001). Point mutation in the mouse glucocorticoid receptor preventing DNA binding impairs spatial memory. Proc Natl Acad Sci USA 98: 12790-12795.

Owens MJ, Nemeroff CB (1991). Physiology and pharmacology of corticotropin-releasing factor. Pharmacol Rev 43: 425-473.

Papolos DF, Edwards E, Marmur R, Lachman HM, Henn FA (1993). Effects of the antiglucocorticoid RU 38486 on the induction of learned helpless behavior in Sprague-Dawley rats. Brain Res 615: 304-309.

Pavlides C, Watanabe Y, Magariños AM, Mc Ewen BS (1995). Opposing roles of type I and type II adrenal steroid receptors in hippocampal long-term potentiation. Neuroscience 68: 387-394.

Ratka A, Sutanto W, Bloemers M, de Kloet ER (1989). On the role of brain mineralocorticoid (type I) and glucocorticoid (type II) receptors in neuroendocrine regulation. Neuroendocrinology 50: $117-123$.

Spencer RL, Kalman BA, Cotter CS, Deak T (2000). Discrimination between changes in glucocorticoid receptor expression and activation in rat brain using western blot analysis. Brain Res $\mathbf{8 6 8}$ 275-286.

Spencer RL, McEwen BS (1997). Impaired adaptation of the hypothalamic-pituitary-adrenal axis to chronic ethanol stress in aged rats. Neuroendocrinology 65: 353-359.

Spencer RL, Young EA, Choo PH, McEwen BS (1990). Adrenal steroid type I and type II receptor binding: estimates of in vivo receptor number, occupancy and activation with varying level of sterioid. Brain Res 514: 37-48.

Takamori K, Kawashima N, Chaki S, Nakazato A, Kameo K (2001). Involvement of the hypothalamus-pituitary-adrenal axis in antidepressant activity of corticotrophin-releasing factor subtype 1 receptor antagonists in the rat learned helplessness test. Pharmacol Biochem Behav 69: 445-449. 